\title{
Potential impacts of wind farms on migratory birds crossing Spain
}

\author{
JOSÉ LUIS TELLERÍA
}

\begin{abstract}
Summary
Over recent years, Spain has undergone a huge expansion in the number of wind farms, many of which extend across regions crossed by migratory birds that winter in the Iberian Peninsula and Africa. This paper explores the potential impact these structures have on the massive flow of birds along the western Pyrenean flyway. Ringing recoveries of migratory Wood Pigeons Columba palumbus were used in the study to depict the movements of migratory birds and these were then compared to the distribution of wind farms. The main flow of pigeons $(50 \%$ of ringing recoveries) was concentrated in a belt $50 \mathrm{~km}$ wide. Although the wind farms were mainly distributed outside this central belt, they intercepted an adjacent sector where a considerable number of ringed pigeons $(30 \%)$ were recorded. This means that the two central bands (100 km wide) accounted for around $80 \%$ of the total number of Wood Pigeons crossing the region. These results suggest the need for a scrupulous evaluation of the potential impact of wind farms on migratory birds along this flyway, particularly the cumulative effect on populations crossing the region regularly. In view of the rapid expansion of wind farms in northern Spain, enforcement of the application of EU regulations on preventive measures to protect migratory species is urgently needed.
\end{abstract}

\section{Introduction}

The expansion of wind farms throughout Europe to cope with the rising demand for energy in a world constrained by the greenhouse effect has had a series of environmental impacts (e.g. habitat destruction, visual impact, roads, power lines) that need to be evaluated. In the context of this study, the impact of wind farms is a conservation issue, as birds and other flying animals moving too close to the turbines and associated infrastructure run the risk of being disturbed or killed (Percival 2005, Drewitt and Langston 2006, Fox et al. 2006).

Despite methodological difficulties, it is possible to explore the link between certain features of wind farms (e.g. number, distribution and type of turbines) and their impact on local wildlife populations (Fox et al. 2006, Band et al. 2007, Morrison et al. 2007, Steward et al. 2007). However, evaluating the cumulative effect of these structures on migratory birds is more difficult because of the distances flown between breeding grounds and wintering areas. It has therefore been proposed that, rather than focusing on local effects, an attempt should also be made to assess the cumulative impact of wind farms on birds throughout their migratory routes (Fox et al. 2006). This approach implies understanding how birds move along the flyways (Desholm and Kahlert 2005), and identifying areas where they may be particularly exposed to the effects of wind farm structures, such as migratory bottlenecks.

Each autumn, millions of birds migrate from their breeding areas in western Europe towards their wintering grounds in the Iberian Peninsula and Africa. These massive flows of migrant birds become especially concentrated at geographical bottlenecks, such as coastlines and mountain passes (Alerstam 1990). Birds converge over the Atlantic coast of France and reach Spain through the 
western Pyrenees, which is the main gateway for migrants entering the Iberian Peninsula (Moreau 1956, Bernis 1966-1971). The importance of this flyway for European migrant birds, which range from the more conspicuous species, such as Wood Pigeons Columba palumbus, Black Storks Ciconia nigra and Common Cranes Grus grus to the many small passerines (Bernis 1966-1971, Fernández-Cruz 1981, Madroño et al. 1992, Galarza and Tellería 2003, Urcun 2003) has long been recognised.

The expansion of wind farms in Spain is set to continue. In 2007, there were 530 wind farms capable of producing 14,145 MW. The aim envisaged in the five-year Spanish Plan for Renewable Energies is to reach 20,155 MW in 2010 (Spanish Wind Energy Association, www.aeeolica.org). Not only are these infrastructures occupying increasingly larger areas of the country, many of them are located in areas crossed by the migratory flyway through the western Pyrenees (e.g. Laiolo and Tella 2007), which may create barriers for bird movements. This paper aims to illustrate the potential impact of these structures on birds moving along this migratory flyway by exploring the relationships between the movements of migratory Wood Pigeons and the distribution of wind farms in northern Spain. Along with other migratory birds, several million central European Wood Pigeons cross the western Pyrenees every year to winter in the south-western quarter of the Iberian Peninsula (Purroy 1988, Bea et al. 2003).

\section{Methods}

Ringing recoveries of extra-Iberian migratory Wood Pigeons provided by the Spanish Ringing Scheme $(n=165)$ were used to sample distribution along the Atlantic migratory flyway across the Iberian Peninsula. Wood Pigeons are actively hunted in Spain during the autumn migration and in winter (there are more than one million hunters throughout the country) so it can be assumed that the distribution of ringing recoveries will reflect the true distribution of migratory flyways and wintering areas (Bairlein 2001). The geographical pattern of wind farms, together with the number of turbines and power output per farm (in MW), was obtained from the official website of the Spanish Wind Energy Association (www.aeeolica.org). Both the ringing recoveries and the distribution of wind farms were updated to September 2007.

After the pigeon recoveries and wind farms had been mapped, a series of parallel belts $50 \mathrm{~km}$ wide was drawn, following the SW direction taken by migratory pigeons. This made it possible to define a number of migratory belts to compare the intensity of pigeon movements (assessed by the number of ringing recoveries per belt) and the accumulated risk of interferences from wind farms (assessed by the number of wind farms, turbines or installed power per belt). These analyses were performed with ArcGis-ArcMap ${ }^{\circledR}$ 9.1.

\section{Results}

The Wood Pigeons reached Spain after crossing the western side of the Pyrenees. They flew along a corridor $200-250 \mathrm{~km}$ wide located between the highest mountains in the east and the Atlantic shoreline in the west. After entering Spain, they encountered several mountain ranges before reaching the south-western lowlands to winter. Shortly after crossing the Pyrenees, they crossed an area that has one of the highest densities of wind farms in Spain ( 169 wind farms, 4,838 turbines and 4,190MW; Table 1, Figure 1).

The main flow of migratory Wood igeons was concentrated in a belt $50 \mathrm{~km}$ wide (Belt C, with 52 out of the 100 recoveries recorded in the region; Table 1 ). Away from this belt, there was a decrease in the density of recoveries towards the west but not towards the east, where Belt D had 26 recoveries. This means that the two central belts (C and D) accounted for around $80 \%$ of the total number of ringing recoveries (Figure 1 ).

The distribution of wind farms did not overlap significantly with that of migratory pigeons (ringing recoveries vs. wind farms; $\chi^{2}{ }_{5}=401, P<$ o.oo1). However, despite the uneven spatial 
Table 1. Distribution of Wood Pigeon ringing recoveries, wind farms, turbines and installed power in the six 50-km wide migratory belts represented in Figure 1 .

\begin{tabular}{lcccccc}
\hline Migratory belt & A & B & C & D & E & F \\
\hline Number of ringing recoveries & 2 & 14 & 52 & 26 & 6 & 0 \\
Number of wind farms & 23 & 14 & 10 & 47 & 40 & 35 \\
Number of turbines & 502 & 330 & 454 & 1,277 & 991 & 1,284 \\
Power (MW) & 444.4 & 295.7 & 370.5 & $1,139.0$ & 804.3 & $1,138.6$ \\
\hline
\end{tabular}

distribution of birds and wind farms, Belt D, which had the highest density of wind farms, received the second most abundant flow of Wood Pigeons (Table 1 ). Therefore, this belt appears to be critical with respect to protection of the migratory flow.

\section{Discussion}

Wood Pigeons have been used as a model species in this study to illustrate the way migratory land birds move along the Pyrenean flyway in northern Spain. Although the use of surrogate
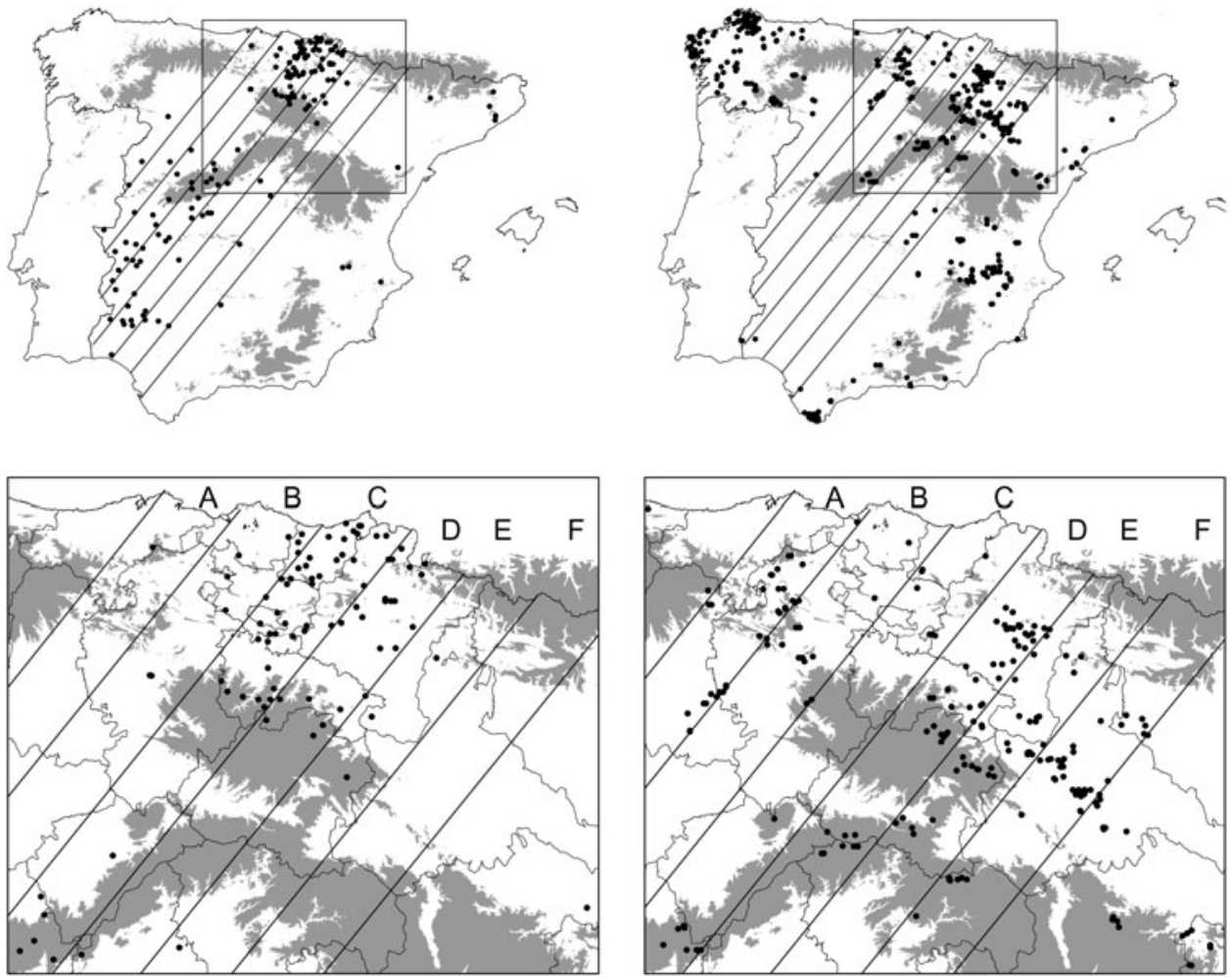

Figure 1. Above. Distribution of extra-Iberian migratory Wood Pigeon ringing recoveries (left) and wind farms (right) in Spain. The study area and the belts outlined to explore potential birdwind farm interactions are also shown. Below: Distribution of ringing recoveries (left) and wind farms (right) in the study area. Migratory belts, elevations over $1000 \mathrm{~m}$ (grey) and administrative units (provinces) are also represented. 
species is a matter of some discussion (Caro and ÓDoherty 1999), the results from the study describe the already-known general pattern of bird movements in the western Pyrenean corridor (see Introduction) and support the view that this area may be considered a migratory bottleneck which puts both this particular species and other migratory birds potentially at risk due to the ongoing expansion of wind farms. From a conservation perspective, three main conclusions can be drawn from this information.

The first concerns the concentration of wind farms in a key region for birds moving across the Iberian Peninsula. While the effects of wind farms on migratory land birds are not yet fully understood, it is commonly accepted that these will vary according to the particular location and the species. For instance, Barrios and Rodriguez (2004) and De Lucas et al. (2007) reported that raptors moving across the Strait of Gibraltar (a bottleneck for soaring birds with a high density of wind farms; Figure I) had a certain ability to detect turbines, and collision rates were low. However, Lekuona and Ursúa (2007) reported that several migratory species (Black Kite Milvus milvus, Black Stork, Northern Lapwing Vanellus vanellus, Song Thrush Turdus philomelos, Common Chaffinch Fringilla coelebs and Common Linnet Carduelis cannabina) face situations of high risk when flying near wind farms in northern Spain (Belt D, Figure I). In fact, for all species in this zone, both migratory and sedentary, collision rates ranging from four to 64 birds/turbine/ year have been reported (Lekuona 2001, Onrubia et al. 2002). This could produce a significant loss of individuals in a sector where many migratory birds move twice a year across several $50-\mathrm{km}$ wide belts occupied by more than 1,000 turbines (Figure 1 ). The cumulative effect of collisions on rare or endangered species is one of the most recurrent concerns when assessing the negative effect of wind farms on wildlife (Drewitt and Langston 2006, Hüppop et al. 2006).

The second conclusion refers to the regional and local distribution of wind farms and the possibilities of launching preventive measures to protect migratory birds. The fact that the density of wind farms and turbines in Belt $\mathrm{C}$, the most important for migrants (Table $\mathrm{I}$ ), is still very low opens up the possibility of restricting new construction in this area, the solution suggested in other European countries to protect migratory flyways (Hüppop et al. 2006). It also offers the option of carrying out a scrupulous assessment of any impact future projects may have on this belt, particularly the potential effects of location, orientation, local topography, weather and wind farm design (Morrison et al. 2007). Although there is a lack of studies on the effects of local topography on the collision rates of migrants in this region (especially the role played by elevation, slope orientation and funnelling), it is known that mountain passes are particularly sensitive areas for concentrations of migratory birds (Alerstam 1990) which are driven to these passes in large numbers by the funnel effect of surrounding mountain slopes. In fact, in the mountains of northern Spain, such passes have traditionally been used by hunters to shoot migrating Wood Pigeons, thrushes and other birds. Unfortunately, some of the passes are already surrounded by wind farms located on the windy ridges of hills and mountains (Figure 1 ), one of the most frequent locations of wind farms in Spain (Spanish Wind Energy Association; www.aeeolica.org). The effect of these northern Spanish wind farms as barriers to migratory bird flows and collision spots for certain species is not yet understood, although some reports suggest they constitute a disturbance to Wood Pigeons and other migratory birds (Camiña 2002).

The final conclusion is that all potential construction sites in this region should be considered as part of an integral assessment framework (e.g. Exo et al. 2003, Fox et al. 2006). This implies coordination at all levels (provincial, autonomous and central) between different Spanish administrations involved in wind farm concessions in order to prevent the cumulative effects of wind farms on migratory birds. This is all the more important, given that evaluation of the cumulative impacts of multiple wind farms and other developments along migratory flyways is a requirement of EU environmental impact assessment procedures (Directives 85/337/EEC and 97/II/EC) (Fox et al. 2006). It should also be pointed out that under Directive 2001/42/EC national governments of European Union countries are required to undertake strategic environmental assessments of any national wind energy plans that have a potentially adverse impact on wildlife (Fox et al. 2006). Given the international nature of migratory bird populations 
crossing northern Spain, the current situation would seem to be highly appropriate for enforcing the application of EU regulations on the protection of migratory species (e.g. Bonn Convention, Directive 79/409/EEC and its amending acts, Directive 92/43/EEC).

\section{Acknowledgements}

The Spanish Ringing Scheme (Oficina de Anillamiento, DGCN, Ministerio de Medio Ambiente) provided ringing recovery data and Alma Román prepared the data on wind farm distribution. A draft version of this manuscript was considerably improved by Aitor Galarza. This research was funded by the Spanish Ministry of Education and Science (project CGL2004-02744/BOS).

\section{References}

Alerstam, T. (1990) Bird migration. Cambridge, UK: Cambridge University Press.

Bairlein, F. (2001) Results of bird ringing in the study of migration routes and behaviour. Ardea 89: 7-19.

Band, W., Madders, M. and Whitfield, D. P. (2007) Developing field analytical methods to assess avian collision risk at wind farms. Pp. $259-275$ in M. De Lucas, G. F. E. Janss and M. Ferrer, eds. Birds and wind farms. Risk assessment and mitigation. Madrid: Quercus.

Barrios, L. and Rodriguez, A. (2004) Behavioural and environmental correlates of soaring bird mortality at on-shore wind turbines. J. Appl. Ecol. 41: 72-81.

Bea, A., Beitia, R. and Fernández, J. M. (2003) The census and distribution of wintering woodpigeons Columba palumbus in the Iberian Peninsula. Ornis Hungarica 12-13: 157-167.

Bernis, F. (1966-1971) Aves migradoras ibéricas. Volumes I-VII, Madrid: Sociedad Española de Ornitología.

Camiña, A. (2002) Impacto de los parques eólicos (Cabi-Monteros y Escurrillo) en la migración de la paloma torcaz (Columba palumbus) y otras aves en la Sierra de la Hez. Logroño: Gobierno de La Rioja.

Caro, T. M. and O'Doherty, G. (1999) On the use of surrogate species in conservation biology. Conserv. Biol. 13: 805-814.

De Lucas, M., Janss, G. F. E. and Ferrer, M. (2007) Wind farm effects on birds in the Strait of Gibraltar. Pp. 219-227 in M. De Lucas, G. F. E. Janss and M. Ferrer, eds. Birds and wind farms. Risk assessment and mitigation. Madrid: Quercus.
Desholm, M. and Kahlert, J. (2005) Avian collision risk at an offshore wind farm. Biol. Lett. 1: $296-298$

Drewitt, A. L. and Langston, R. H. W. (2006) Assessing the impacts of wind farms on birds. Ibis 148: 29-42.

Exo, K. M., Hüppop, O. and Garthe, S. (2003) Birds and offshore wind farms: a hot topic in marine ecology. Wader Study Group Bull. 100: 50-53.

Fernández-Cruz, M. (1981) La migración e invernada de la Grulla Común (Grus grus) en España. Resultados del proyecto Grus (Crane Project). Ardeola 26-27: 1-164.

Fox, A. D., Desholm, M, Kahlert, J., Christensen, T. K. and Petersen, I. K. (2006) Information needs to support environmental impact assessment of the effects of European marine offshore wind farms on birds. Ibis 148: 129-144.

Galarza, A. and Tellería, J. L. (2003) Linking processes: effects of migratory routes on the distribution of abundance of wintering passerines. Anim. Biodivers. Conserv. 26: 19-27.

Hüppop, O., Dierschke, J., Exo, K. M., Fredrich, E. and Hill, R. 2006 Bird migration studies and potential collision risk with offshore wind turbines. Ibis 148: 90109.

Laiolo, P. and Tella, J. L. (2006) Fate of unproductive and unattractive habitats: recent changes in Iberian steppes and their effects on endangered avifauna. Environ. Conserv. 33: 223-232.

Lekuona, J. (2001) Uso del espacio por la avifauna y control de la mortalidad de aves y murciélagos en los parques eólicos de 
Navarra durante un ciclo anual. Pamplona: Departamento de Medio Ambiente, Ordenación del Territorio y Vivienda del Gobierno de Navarra.

Lekuona, J. and Ursúa, C. (2007) Avian mortality in wind power plants of Navarra (Northern Spain). Pp. 177-192 in M. De Lucas, G. F. E. Janss and M. Ferrer, eds. Birds and wind farms. Risk assessment and mitigation. Madrid: Quercus.

Madroño, A., Palacios, C. J. and De Juana, E. (1992) La migración de la Cigüeña Negra (Ciconia nigra) a través de España peninsular. Ardeola 39: 9-13.

Moreau, R. E. (1956) The Iberian Peninsula and migration. Bird Study 3: 1-25.

Morrison, M. L., Sinclair, K. C. and Thelander, C. G. (2007) A sampling framework for conducting studies of the influence of wind energy developments on birds and other animals. Pp. 101-116 in M. De Lucas, G. F. E Janss and M. Ferrer, eds. Birds and wind farms. Risk assessment and mitigation. Madrid: Quercus.

Onrubia, A., Villasante, J., Balmorí, A., Sáenz de Buruaga, M., Canales, F. and Campos, M. A. (2002) Estudio de la incidencia sobre la fauna -aves y quirópteros- del parque eólico de Elgea (Alava). Vitoria: Eólicas de Euskadi.

Percival, S. (2005) Birds and wind farms: what are the real issues? British Birds 98: 194-204.

Purroy, F. J. (1988) Sobre la invernada de la Paloma Torcaz (Columba palumbus) en Iberia. Pp: 137-151 in J. L. Tellería, ed. Invernada de aves en la Península Ibérica. Madrid: Sociedad Española de Ornitología.

Steward, G. B., Pullin, A. S. and Coles, C. F. (2007) Poor evidence-base for assessment of wind farm impacts on birds. Environ. Conserv. 34: 1-11.

Urcun, J. P. (2003). The autumn migration of the black stork (Ciconia nigra) through the Pyrenees. Aves 40: 140-154.

\section{JOSÉ LUIS TELLERÍA}

Departamento de Zoología y Antropología Física, Facultad de Ciencias Biológicas, Universidad Complutense, 28040 Madrid, Spain. E-mail: telleria@bio.ucm.es

Received 24 February 2008; revision accepted 5 September 2008 